\title{
Evaluation of Larvicidal Activities of Parthenium Hysterophorus L. Against Anopheles Arabiensis (Diptera: Culicidae), the Major Malaria Vector in
} Ethiopia

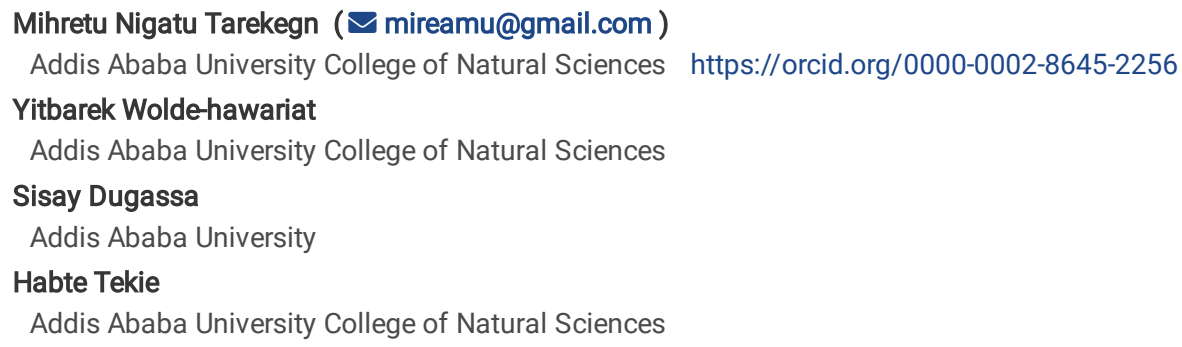

Research

Keywords: Anopheles arabiensis, Phytochemical, Parthenium hysterophorus, Larvicidal, Extract, Malaria

Posted Date: May 28th, 2020

DOl: https://doi.org/10.21203/rs.3.rs-31187/v1

License: (a) (1) This work is licensed under a Creative Commons Attribution 4.0 International License. Read Full License

Version of Record: A version of this preprint was published at International Journal of Tropical Insect Science on November 2nd, 2020. See the published version at https://doi.org/10.1007/s42690-020-00344-z. 


\section{Abstract}

Background: Malaria is a leading public health problem in Ethiopia despite the implementation of effective indoor vector control strategies over several decades. Vector control operations in the country largely depend on the application of Indoor Residual Spraying (IRS) of synthetic insecticides and Long Lasting Insecticidal Nets (LLINs) which resulted in a significant reduction in the malaria burden. The spread of resistance to insecticides in these indoor vector control tools in vector species is a serious challenge. Alternatively, reports indicate that botanicals which are relatively safe possess toxic compounds with high larvicidal activities. However, there are limited evidences on the larvicidal effect of botanicals against the malaria vectors, Anopheles arabiensis . This study aimed to evaluate the larvicidal activities of the extracts of the roots, stems, and leaves of Parthenium hysterophorus against the 4 th instar larvae of An. arabiensis .

Methods: Field collected leaves, stems and root parts of P. hysterophorus were dried and separately ground to powder and extracted in petroleum ether, hexane, acetone, and ethanol solvents. The extracts were concentrated using a Rota evaporator, and stock solutions were subject to serial dilutions for use as test concentrations. Laboratory reared 4 th instar larvae of An. arabiensis were used for the larvicidal bioassays. Mortality data were subjected probit analysis to determine LC 50 and LC 90 of the extracts.

Results: The results showed that there were significant differences in percentage larval mortalities $(P<0.05)$ among different concentrations of the leaf, stem, and root solvent extracts, respectively. Hexane extracts of leaves and stem of P. hysterophorus at 480ppm caused the highest mortality of 4 th larval instar of An. arabiensis ( $85 \%$ and $96.7 \%$, respectively) compared to those of ethanolic, acetone, and petroleum ether extracts of these plant parts. Petroleum ether extracts of the root of P. hysterophorus were the most effective in causing very high larval mortality at 360ppm and $480 \mathrm{ppm}$ ( $98.3 \%$ ). The LC 50 value of petroleum ether root extract (10.7ppm) and LC 90 value of petroleum ether root extract (105.5ppm) were significantly lower than those of ethanol, acetone, and hexane root extracts, respectively.

Conclusion: Petroleum ether root extract of P. hysterophorus has remarkably high larvicidal potential against 4 th instar larvae of An. arabiensis which could be exploited for malaria vector control. Further studies on the larvicidal efficacy of the extracts under field conditions and identification of the bioactive components in the root parts of this weed plant are recommended.

\section{Introduction}

Mosquitoes are known to transmit human diseases including malaria, dengue fever, yellow fever, and filariasis [1, 2]. Globally, 212 million of malaria cases were reported in 2015 leading to 429,000 deaths, of which (92\%) is reported from Africa [2]. Over $70 \%$ of the global malaria burden was estimated to have occurred in children less than 5 years old [2]. Plasmodium falciparum and $P$. vivax cause most of the malaria burden worldwide, particularly in sub-Saharan Africa [3-6]. Adult female mosquitoes of the genus Anopheles are known to transmit malaria. About 20 Anopheles species are known to transmit malaria in sub-Saharan Africa. In Ethiopia, An. arabiensis, a member of the An. gambiae complex, is the primary malaria vector, whereas An. funestus, An. pharoensis, and An. nili serve as secondary vectors [7].

A recent malaria indicator survey conducted in Ethiopia indicated that there is scaling up of the conventional malaria control strategies, mainly in the coverage of long-lasting insecticide treated bed nets (LLINs) and indoor residual spray (IRS). However, malaria is still a leading public health problem in the country [8]. Both these mosquito control strategies are based on the use of synthetic insecticides. However, the high cost of synthetic insecticides, and their adverse impacts on the environment and human health compromise the use of synthetic insecticides [9]. In Ethiopia, the development of insecticide resistance in the mosquito vectors and widespread multidrug resistant Plasmodium parasites are the challenges to the malaria control program. Studies indicate that $A n$. arabiensis has developed resistance to a number of insecticides including DDT, permethrin, deltamethrin, and malathion [10, 11, 12]. The development of a behavioral resistance which led to an increased outdoor biting and resting proportion of An. arabiensis might play a significant role in the residual malaria transmission in Ethiopia. Furthermore, a shift in biting activities of $A$. arabiensis from late to early evening hours before people retire to bed has also been reported from Ethiopia [13]. Therefore, there is an urgent need to find sustainable alternatives or complements to vector management strategies.

Botanical larvicides are among such alternatives to synthetic insecticides which could be used against malaria vectors [14, 15]. Botanical larvicides are preferred over the conventional chemical insecticides because they are relatively ecologically safe, target-specific, and biodegradable properties [16].

P. hysterophorus (Asteraceae) is an extremely abundant invasive weed which causes severe economic loss, health problems, and habitat destruction [17, 18]. This species is reported to release allelochemicals that inhibit the germination and growth of field grasses and other plants. On the other hand, $P$. hysterophorus contain important bioactive compounds, such as sesquiterpene lactones, flavonoid glycosides and pinenes responsible for its ethnobotanical value $[14,19]$. Previous studies reported that stem, leaf and root extracts of $P$. hysterophorus have larvicidal effects against Culex quinquefasciatus and Aedes aegypti $[20,21]$. Thus, it is important to explore full profile larvicidal activities of $P$. hysterophorus against the larvae of mosquitoes for use in aquatic breeding sites.

To our knowledge, there are limited published reports on the larvicidal effects of root, stem and leaf extracts of $P$. hysterophorus against African malaria vectors, An. arabiensis. This study aimed to evaluate the larvicidal efficacy ethanolic, acetone, hexane and petroleum ether extracts $P$. hysterophorus root, stem and leaf parts against the 4th instar larvae of An. arabiensis under laboratory conditions.

\section{Methods}




\section{Collection and processing plant parts}

Parthenium hysterophorus (here after $P$. hysterophorus) whole plants were collected from the suburb areas of Akaki-Kaliti, Addis Ababa, Ethiopia. The plant specimens were identified as $P$. hysterophorus and voucher specimens have been deposited at the National Herbarium, Addis Ababa University. The fresh leaves, stem and root parts of $P$. hysterophorus were washed with tap water and dried under shade separately at room temperature $\left(27 \pm 2{ }^{0} \mathrm{C}\right)$. Finally, the dried leaf, stem and root parts were manually ground with mortar and pestle and sieved thoroughly to get a fine powder.

\section{Plant extraction method}

Ten gram of P.hysterophorus leaf, root and stem powder were separately weighed and soaked in $100 \mathrm{ml}$ of petroleum ether, hexane, acetone, and ethanol, using Erlenmeyer flasks, placed on the orbital shaker (VWR, USA) for 24hours and were filtered through Whatman no. 1 filter paper (Whatman International Ltd., Maidstone, England). The crude extract filtrate were concentrated using a vacuum evaporator under low pressure. After complete evaporation of the solvent, $1 \mathrm{~g}$ of the concentrated extract was dissolved in $1000 \mathrm{ml}$ of distilled water $(1000 \mathrm{ppm})$ and stored as the stock solution in a refrigerator at $4^{\circ} \mathrm{C}$. The stock solution was subject to serial dilution to prepare the desired concentrations of the extracts for the larvicidal bioassay.

\section{Mosquito rearing}

A colony of An. arabiensis was reared at $28 \pm 1{ }^{\circ} \mathrm{C}$ and $70-80 \% \mathrm{RH} ; 12: 12 \mathrm{~h}$ light: dark photoperiod in the insectary as recommended by WHO [12]. Newly emerged adults were fed on $10 \%$ sucrose solution soaked in cotton wicks. Female mosquitoes were provided with restrained rabbit as a blood source (1-2 $\mathrm{h}$ daily). Glass Petri dishes with wet filter paper placed inside the cage were used for oviposion and eggs were transferred to enamel trays with distilled water for egg hatching. The newly hatched larvae were reared on $30 \mathrm{mg} /$ tray diet consisting of finely ground dog biscuits and yeast (3:2 w/w) in enamel trays $(25 \mathrm{~cm} \times 30 \mathrm{~cm} \times 5 \mathrm{~cm})$ containing de-chlorinated water. Pupae were collected daily and transferred to rearing cages for adult emergence.

\section{Larvicidal bioassay}

Fourth instar larvae of $A n$. arabiensis were used for larvicidal bioassay performed at $(28 \pm 1){ }^{0} \mathrm{C}$ following the procedure described by WHO [22]. Test solvent extracts of root, stem and leaf parts of $P$. hystrosporous at concentrations of 40 ppm, 80 ppm, 120 ppm, 160 ppm, 240 ppm, 360 ppm, and 480 ppm were applied into separate glass beakers $(200 \mathrm{ml})$ containing 20 4th instar An. arabiensis larvae in $100 \mathrm{ml}$ of distilled water. Twenty 4th instar larvae in glass beaker containing $100 \mathrm{ml}$ distilled water without any test extracts were used as controls. Dried yeast powder (20 mg) was added per glass beakers as a food of larvae for both treatment and control groups. The experiment was set up in a completely randomized design with three replications [23]. Larval mortality was recorded at the end of $24 \mathrm{~h}$ exposure time. The larvae were considered as dead when they failed to move after probing with a needle in the cervical region.

\section{Phytochemical analysis of $P$. hysterophorus extracts}

The solvent extracts of the leaf, stem and root parts of $P$. hystrophorous were analyzed to determine their phytochemical composition which could be responsible for larvicidal activities based on the procedures described in Harborne [24]. Accordingly, Mayer's test and Benedict's test were used to determine the presence of alkaloids and reducing sugars, respectively. Similarly, Foam test, Ferric chloride test (neutral 5\%), Ferric chloride test (0.1\%), and Ammonia test were used for detecting the presence of saponins, phenolic compounds, tannins, flavinoids, respectively. Salkowski test (for the presence of terpenoids) and Acid test (for the presence of phlobatannins) were also carried out for the plant extracts used in the larvicidal bioassays.

\section{Data analysis}

The larval mortality recorded after $24 \mathrm{~h}$ exposures were expressed as percentage of the number of larvae exposed to the treatments. If the observed mortality in the control is between 5-20\%, mortality data was corrected using Abbot's formula [25]. When control mortalities are greater than $20 \%$, experiments were discarded [22]. Data were analyzed using SPSS version 20 software (Armonk, NY: IBM Corp). A one-way ANOVA was used to test differences in percent larval mortality among concentrations of solvent extract. When difference are significant, means were separated using Tukey HSD test $(a=0.05)$. Larval mortality data from bioassays with acetone, hexane and petroleum ether extracts of $P$. hysterophorus plant parts were subjected to a probit analysis to determine the $\mathrm{LC}_{50}$ and $\mathrm{LC}_{90}$ values for each solvent extract used in the bioassays.

\section{Results}

\section{Larvicidal efficacy of P. hysterophorus leaf extracts}

The data on larvicidal effects the leaf extracts of $P$. hysterophorus revealed that there were significant differences in percent laraval mortality among different concentrations of hexane, acetone and petroleum ether leaf extracts, respectively $(P<0.05 ;$ Fig. 1$)$. Hexane and acetone leaf extracts caused markedly high larval mortalities at 480 ppm concentrations ( $85 \%$ and $70 \%$ respectively) (Fig. 1B, 1C). Petroleum ether leaf extracts showed moderate larval toxicity at $360 \mathrm{ppm}$ and $480 \mathrm{ppm}$ concentrations (56.7\% and 63.3\%, respectively) (Fig. 1A). The LC $_{50}$ of acetone, petroleum ether, and hexane extract of leaf of $P$. hysterophorus were 478 ppm, 393 ppm, 368 ppm respectively. (Table 1). Ethanolic leaf extracts of $P$. hysterophorus caused low larval mortalities (< $50 \%)$ and were not that effective against 4th instar $A n$. arabiensis larvae ( $P>0.05$; Fig. 1D). 
Table 1

Larvicidal activity of solvent extract of $P$. hysterophorus parts against 4th instar larvae of An.arabiensis.

\begin{tabular}{|c|c|c|c|c|c|}
\hline Plant parts & Solvent & $\begin{array}{l}\mathrm{LC}_{50}(\mathrm{ppm}) \\
(\mathrm{LCL}-\mathrm{UCL})\end{array}$ & $\begin{array}{l}\mathrm{LC}_{90}(\mathrm{ppm}) \\
(\mathrm{LCL}-\mathrm{UCL})\end{array}$ & $X 2(d f=5)$ & Regression equation \\
\hline \multirow[t]{5}{*}{ Leafs } & Hexane & 368 & 809.2 & 8.9 & $Y=3.75 x-9.6$ \\
\hline & & (270.3-758.3) & $(496.2-6053.2)$ & & \\
\hline & Acetone & 478 & 1358.2 & 8.6 & $Y=2.8 x-7.6$ \\
\hline & Petroleum ether & 393.1 & 1352.6 & 7.2 & $Y=2.4 x-6.2$ \\
\hline & & $(300.3-619.0)$ & (791.9-4227.7) & & \\
\hline \multirow[t]{3}{*}{ Stem } & Hexane & 112.4 & 331.9 & 10 & $Y=2.7 x-5.6$ \\
\hline & & $(61.4-167.6)$ & $(211.9-1120.1)$ & & \\
\hline & & $(98.9-572.5)$ & (332.4-68176.7) & & \\
\hline \multirow[t]{6}{*}{ Root } & Hexane & 87.9 & 338.3 & 9 & $Y=2.2 x-4.2$ \\
\hline & & $(32.9-136.7)$ & (203.2-1713.3) & & \\
\hline & Acetone & 342.1 & 769.7 & 18.8 & $Y=3.6 x-9.2$ \\
\hline & & $(208.7-2514.2)$ & $(418.4-558486.5)$ & & \\
\hline & Petroleum ether & 10.7 & 105.5 & 0.89 & $Y=1.3 x-1.3$ \\
\hline & & $(0.02-31.1)$ & $(45.7-238.1)$ & & \\
\hline
\end{tabular}

\section{Larvicidal efficacy of P. hysterophorus stem extracts}

There were significant differences in percent larval mortalities among different concentrations of petroleum ether, hexane, acetone and ethanol extracts of stem of $P$. hysterophorus $(\mathrm{P}<0.05$; Fig. 2). Petroleum ether and hexane stem extracts showed appreciably high percent larval mortalities at 360 ppm and 480 ppm ( $90 \%$ and $85 \%-97 \%$ respectively) (Fig. 2A; $2 B$ ). Hexane stem extracts also showed considerable larval mortality (70\%-80\%) at lower concentrations $\left(120\right.$ ppm-240 ppm) (Fig. 2B). Hexane stem extracts $\left(\mathrm{LC}_{50}=112.4 \mathrm{ppm}\right)$ and petroleum ether stem extracts $\left(\mathrm{LC}_{50}=196.3 \mathrm{ppm}\right)$ showed moderate larvicidal activities (Table 1). Similarly, acetone stem extracts were effective resulting in $76 \%$ mortality but only at relatively higher concentrations (360 ppm and 480 ppm) (Fig. 2C), with $\mathrm{LC}_{50}=259.4 \mathrm{ppm}$ and $\mathrm{LC}_{90}=1814.6 \mathrm{ppm}$ (Table 1).

Ethanol extracts of stem of $P$. hysterophorus only cause relatively low mortalities (below 50\%) at all the concentrations tested in the bioassays, and could not be considered for toxicological applications (Fig. 2D).

\section{Larvicidal efficacy of P. hysterophorus root extracts}

The data on larvicidal activities of extracts of $P$. hysterophorus revealed statistically significant differences in percent larval mortality among different concentrations of acetone, hexane and petroleum ether root extracts, respectively $(P<0.05)($ Fig. 3$)$.

Petroleum ether root extracts caused 93\% -98\% larval mortality of 4th instar An. arabiensis larvae at concentration $\geq 160$ ppm, and lower concentrations (40 ppm and $120 \mathrm{ppm}$ ) also resulted in $80 \%-82 \%$ larval mortalities (Fig. 3A). Petroleum ether root extracts were effective in a dose dependent manner with $\mathrm{LC}_{50}=10.7 \mathrm{ppm}$ and $\mathrm{LC}_{90}=105.5 \mathrm{ppm}$ (Table 1). Comparatively high larval mortalities ( $85.0 \%$ and $\left.96.7 \%\right)$ were achieved with $360 \mathrm{ppm}$ and $480 \mathrm{ppm}$ hexane root extracts, respectively (Fig. 3B). Larval mortalities of 72\%- 78.3\% were recorded using 120 ppm-240 ppm hexane root extracts (Fig. 3B). Hexane root extracts also produced high larval mortality with $\mathrm{LC}_{50}=87.9 \mathrm{ppm}$ and $\mathrm{LC}_{90}=338.3 \mathrm{ppm}($ Table 1$)$.

Acetone root extracts were also effective in achieving $88.3 \%$ larval mortality at $480 \mathrm{ppm}$, but lower concentrations showed inferior larvicidal activities (Fig. 3C), with $\mathrm{LC}_{50}=342.1 \mathrm{ppm}$ and $\mathrm{LC}_{90}=769.7 \mathrm{ppm}$ (Table 1). Ethanol extracts of the root parts of $P$. hysterophorus showed relatively low larvicidal activities (with only $53 \%$ mortality at 480 ppm) (Fig. 3D). 


\section{Phytochemical analysis extracts of P. hysterophorus}

Secondary plant metabolites including saponin, phenolic compounds, terpenoids, alkaloid and phlobatannins were detected from the phytochemical analysis of $P$. hysterophorus (Table 2). However, reducing sugars were not detected from all plant parts tested using Benedict's test.

Table 2

Phytochemical composition of P. hysterophorus leaf, stem and root

\begin{tabular}{|c|c|c|c|c|c|c|c|c|c|c|c|c|}
\hline \multirow[t]{2}{*}{ Tested components } & \multicolumn{5}{|c|}{ Root Stem Leave } & \multirow[b]{2}{*}{ PE } & \multirow[b]{2}{*}{ Ethanol } & \multirow[b]{2}{*}{ Acetone } & \multirow[b]{2}{*}{ Hexane } & \multirow[b]{2}{*}{$\mathrm{PE}$} & \multirow[b]{2}{*}{ Ethanol } & \multirow[b]{2}{*}{ Acetone } \\
\hline & Hexane & PE & Ethanol & Acetone & Hexane & & & & & & & \\
\hline Reducing sugars & - & - & - & - & - & - & - & - & - & - & - & - \\
\hline Saponin & + & + & + & + & - & + & - & + & + & + & + & - \\
\hline PC & - & - & - & - & - & - & - & - & - & - & + & + \\
\hline Tannis & - & - & - & - & - & - & - & - & - & + & + & + \\
\hline Flavonoid & - & + & - & + & + & - & + & & + & - & - & - \\
\hline Terpenoid & + & + & + & - & + & + & + & - & + & + & - & - \\
\hline Phlobatannins & - & + & - & - & - & - & - & - & - & - & - & - \\
\hline Alkaloids & - & + & - & - & - & - & - & - & - & - & + & - \\
\hline
\end{tabular}

\section{Discussion}

This study evaluated the larvicidal activity of ethanol, acetone, hexane, and petroleum ether extracts of the leaf, stem, and root parts of $P$. hysterophorus against the 4th instar larvae of An. arabiensis. The toxic effect of $P$. hysterophorus against the 4th instar larvae of An. arabiensis depends on the solvent type, test concentration of the extract and plant parts. Petroleum ether and hexane extracts of the stem and root of $P$. hysterophorus resulted in relatively high larvicidal activity against 4 th instar larvae of $A n$. arabiensis. High larval mortality ( $\geq 93 \%$ ) was achieved with petroleum ether root extracts at $\geq$ $160 \mathrm{ppm}$ concentrations. Lower concentrations of petroleum ether root extracts (40 ppm and $120 \mathrm{ppm}$ ) also caused appreciably high ( $\geq 80 \%)$ larval mortalities (Fig. 3A) with dose dependent efficacy in toxicity. The $\mathrm{LC}_{90}$ value of Petroleum ether root extracts $\left(\mathrm{LC}_{90}=105.5 \mathrm{ppm}\right.$, Table 1$)$ could be optimized to relatively low concentration formulations for application under field conditions. Hexane root extracts also produced promising efficacy (85.0\% and $96.7 \%$ ) but at relatively higher concentrations $\left(\mathrm{LC}_{90}=338.3 \mathrm{ppm}\right.$; Table 1$)$. The high larvicidal activity of petroleum ether and hexane extracts of the root parts of this plant could be due to the presence of toxic phytochemicals such as saponins, phytosterols, phenols, flavonoids, and tannins, alkaloids and phenolic compounds detected in $P$. hysterophorus plant parts [9, 26-29].

The acetone $\left(\mathrm{LC}_{50}=478 \mathrm{ppm}, \mathrm{LC}_{90}=1358.2\right)$, hexane $\left(\mathrm{LC} 50=368 \mathrm{ppm}, \mathrm{LC}_{90}=809.2 \mathrm{ppm}\right)$ and petroleum ether $\left(\mathrm{LC}_{50}=393.1, \mathrm{LC}_{90}=1352.6 \mathrm{ppm}\right)$ extracts of $P$. hysterophorus leaf part were moderately effective against 4th instar larval of An.arabiensis at higher concentrations and need further evaluation for use as mosquito larvicides under field conditions. In consistent with this result, acetone extracts of Solanum trilobatum leaf against 2 nd instar larvae of Culex quinquefasciatus $\left(\mathrm{LC}_{50}=265.7 \mathrm{ppm}, \mathrm{LC}_{90}=558.3 \mathrm{ppm}\right)$ and Aedes aegypti $\left(\mathrm{LC}_{50}=301.1 \mathrm{ppm}, \mathrm{LC}_{90}=582.3\right.$ ppm $)$ were moderately effective [30]. The methanol extract of Melaleuca cajuputi leaf against Ae. aegypti $\left(\mathrm{LC}_{50}=183.4 \mathrm{ppm}\right.$ and $\left.\mathrm{LC}_{90}=1000 \mathrm{ppm}\right)$ and Ae. albopictus $\left(\mathrm{LC}_{50}=191.8 \mathrm{ppm} \mathrm{LC}_{90}=\right.$ $1000 \mathrm{ppm}$ ) [31], and methanol extract of the Erythrina indica leaf against the larvae of An. stephensi $\left(\mathrm{LC}_{50}=69.43, \mathrm{LC}_{90}=75.13\right)$, Ae. aegypti $\left(\mathrm{LC}_{50}=\right.$ 91.4 ppm, $\left.\mathrm{LC}_{90}=125.5\right)$, and $C$. quinquefasciatus $\left(\mathrm{LC}_{50}=134.3, \mathrm{LC}_{90}=167.14\right)$ were moderately effective [32]. In addition, petroleum ether extract of Cassia fistula and Nicotiana tabacum leaf caused a relatively high mortality of 3 rd instar larvae of $C$. quinquefasciatus with a respective $\mathrm{LC}_{50}$ and $\mathrm{LC}_{90}$ of (203.5 ppm, 542.8 ppm) and (223.9 ppm, 645.5 ppm) [33]. The Ethyl acetate and methanol extract of Sterculia quinqueloba leaf against late 3rd instar larvae of An.gambiae resulted in $\mathrm{LC}_{50}$ and $\mathrm{LC}_{90}$ of $(178.9 \mu \mathrm{g} / \mathrm{ml}, 526.3 \mu \mathrm{g} / \mathrm{ml})$ and $(3762.4 \mu \mathrm{g} / \mathrm{ml}, 63762.4 \mu \mathrm{g} / \mathrm{ml})$ respectively after $24 \mathrm{hours}$ of exposure time [34]. In contradict with this study, Kumar et al., [20] reported that acetone, hexane, petroleum ether and diethyl ether extract of $P$. hysterophorus leaf were not effective against 3rd and 4th instar larvae of Ae.aegypti. This variation could be attributed to the difference in the type of mosquito species involved in the experiment.

Petroleum ether, hexane and acetone extracts of $P$. hysterophorus stem showed a moderate larvicidal activity against the 4th larval instar of $A n$.arabiensis with a respective $\mathrm{LC}_{50}$ and $\mathrm{LC}_{90}$ values of (196.3 ppm, $\left.701.1 \mathrm{ppm}\right),(112.4 \mathrm{ppm}, 331.9 \mathrm{ppm})$ and (259.4 ppm,1814.6) which also need a further field evaluation and screening. Similarly, hexane extract of Achyranthes aspera, Cassia occidentalis, Catharanthus roseus, Lantana camara and Xanthium strumarium stem exhibited a 100\% mortality against 4th instar larvae of Ae. aegypti with LC Ln $_{0}$ and LC 90 of (68.1 ppm, 115.1 ppm), (149.7 ppm,206.3 ppm), (108.2 ppm,184.2 ppm), (89.6 ppm,125.9 ppm) and (460.9 ppm,1074.0 ppm) respectively [35]. Ethyl acetate extracts of Sterculia quinqueloba stem resulted appreciable larvicidal activity against the 3rd instar larvae of Ae. aegypti $\left(\mathrm{LC}_{50}=227.3 \mu \mathrm{g} / \mathrm{ml}, \mathrm{LC}_{90}=642.03 \mu \mathrm{g} / \mathrm{ml}\right)$ and $A n$. gambiae s.s $\left(\mathrm{LC}_{50}=\right.$ $\left.135.4 \mu \mathrm{g} / \mathrm{ml}, \mathrm{LC}_{90}=313.73 \mu \mathrm{g} / \mathrm{ml}\right)$ [34]. Likewise, the respective $\left(\mathrm{LC}_{50}\right.$ and $\left.\mathrm{LC}_{90}\right)$ values of hexane and petroleum ether extract of $P$. hysterophorus stem were (379.8 mg/L, $1314.4 \mathrm{mg} / \mathrm{L})$ and (438.5 mg/L, $870.6 \mathrm{mg} / \mathrm{L})$ against 3rd larval instar of Ae. aegypti [20]. 
A number of studies indicated that root of different plant species have a larvicidal potential against different species of mosquitoes [36-38]. In this study, petroleum ether $\left(\mathrm{LC}_{50}=10.7 \mathrm{ppm}, \mathrm{LC}_{90}=105.5 \mathrm{ppm}\right)$ and hexane $\left(\mathrm{LC}_{50}=87.9 \mathrm{ppm}, \mathrm{LC}_{90}=338.3 \mathrm{ppm}\right)$ extract of $P$. hysterophorus root caused a significant mortality of 4th instar larvae of An. arabiensis, this makes petroleum ether root a most effective of all extracts tested. Likewise, methanol and ethanol extract of Aristolochia saccata root was effective against Ae. albopictus larvae with a respective $\mathrm{LC}_{50}$ and $\mathrm{LC}_{90}$ of (14.5 ppm, $\left.42.7 \mathrm{ppm}\right)$ and $(17.3 \mathrm{ppm}, 58.5 \mathrm{ppm})[39]$. The same study also indicated that methanol $\left(\mathrm{LC}_{50}=31.9 \mathrm{ppm}, \mathrm{LC}_{90}=81.1 \mathrm{ppm}\right)$ and ethanol $\left(\mathrm{LC}_{50}=19.8 \mathrm{ppm}, \mathrm{LC} 90=60.4 \mathrm{ppm}\right)$ extract of Aristolochia saccata root caused a significant mortality of $C x$. quinquefasciatus larvae starting from the lowest concentration. In addition, a significant larval mortality of $C x$. quinquefasciatus was recorded because of petroleum ether extract of Solanum xanthocarpum root $\left(\mathrm{LC}_{50}=41.3\right.$ ppm and $\left.\mathrm{LC}_{90}=111.2 \mathrm{ppm}\right)$ [40]. Furthermore, a high ( $100 \%$ mortality at $200 \mathrm{mg} / \mathrm{L}$ within the 8 th day of exposure time) larvicidal activity of aqueous-ethanoic extracts of Syzgium guineense root against Ae. albopictus was reported [41]. However, this result is by far superior to the larvicidal effect of petroleum ether and hexane extract of $P$. hysterophorus root against the 4th instar larvae of Ae.aegypti ( $\mathrm{LC}_{50}$ and $\mathrm{LC}_{90}$ of $(562.5 \mathrm{mg} / \mathrm{L}, 1232.1 \mathrm{mg} / \mathrm{L})$ and $(432.8 \mathrm{mg} / \mathrm{L}$, $1118.5 \mathrm{mg} / \mathrm{L}$ ) respectively) [20]. This could be due to the difference in mosquito species used for the experiment.

The phytochemical analysis of $P$. hysterophorus showed the presence of major secondary plant metabolites such as saponins, tannins, flavonoid, terpenoid and phlobatannins. Similarly, other studies revealed that $P$. hysterophorus is endowed with various chemical constituents such as, alkaloids, proteins, saponins, tannins, carbohydrate, glycosides, terpenoids, steroids, volatile oils, amino acids, amino sugars, lignans, phenolic compounds, flavonoids, metallic elements, organic acids, terpenoids [21, 26-28, 42].

\section{Conclusion}

Different solvent extracts of $P$. hysterophorus leaves, stems and roots have a larvicidal potential against the 4th instar larvae of $A n$. arabiensis due to the presence of toxic secondary plant metabolites. Particularly, petroleum ether root, petroleum ether stem, hexane stem, and hexane root extract of $P$. hysterophorus possess a high larvicidal potential. The use of plant extracts in insect control offers a safer alternative to synthetic chemicals and can be obtained by the communities easily at a very low cost and used for protection against mosquito borne diseases. There is also a need for promoting the use of plant based larvicides through community based vector control programs. Further studies at larger scales, semi-field and field settings, are important to confirm their efficacies. In addition, screening of the active compounds of the plant which are responsible for its larvicidal activity is recommended.

\section{Abbreviations}

CL: Confidence Limit; DF: Degree of freedom; $\mathrm{LC}_{50}$ : Lethal concentration of the extract which kills $50 \%$ of the fourth instar larvae of An.arabiensis after 24 hours exposure; LC 90: Lethal concentration of the extract which kills $90 \%$ of the fourth instar larvae of An.arabiensis after 24 hours exposure time; $\chi 2$ : chi squire; PC: Phenolic compound; PE: Petroleum ether; ppm: parts per million; SE: Standard error

\section{Declarations}

\section{Ethics approval and consent to participate}

Not applicable

\section{Consent for publication}

Not applicable

\section{Availability of data and materials}

The data sets supporting the conclusions of this article are provided in the manuscript.

\section{Competing Interest}

The authors declare that there is no conflict of interest.

\section{Funding}

This study was financed by Addis Ababa University thematic research project.

\section{Authors' contributions}

MT, HT, YW and SD designed the study.HT, YW and SD supervised and MT conducted the experiments. MT conducted the statistical analyses. MT developed first draft, HT, YW and SD revised the manuscript. All authors read and approved the final manuscript. 


\section{Acknowledgements}

The authors want to acknowledgeDepartment of Zoological science, Addis Ababa University for providing a financial support for this research. We also express our appreciation for Addis Ababa University, Aklilu lemma institute of pathobiology staff members for their technical assistance and providing a mosquito colony for rearing.

\section{References}

1. Benelli G, Jeffries C, Walker T. Biological control of mosquito vectors: past, present, and future. Insects. 2016;7:52.https://doi.org/10.3390/insects7040052

2. World Health Organization. "A global brief on vector-borne diseases."

(2014).https://apps.who.int/iris/bitstream/handle/10665/111008/WHO_DCO_WHD_2014.1_chi.pdf.Accessed 6 February 2018.

3. Howes RE, Battle KE, Mendis KN, Smith DL, Cibulskis RE, Baird JK, Hay SI. Global epidemiology of Plasmodium vivax. Am J Trop Med Hyg. 2016; 28;95:15-34. https://dx.doi.org/10.4269\%2Fajtmh.16-0141

4. Gething PW, Elyazar IR, Moyes CL, Smith DL, Battle KE, Guerra CA, Patil AP, Tatem AJ, Howes RE, Myers MF, George DB, Horby P, Wertheim HF, Price RN, Mueller I, Baird JK, Hay SI. A long neglected world malaria map: Plasmodium vivaxendemicity in 2010. PLoS Neg/ Trop Dis. $2012 ; 6:$ e1814. https://dx.doi.org/10.1371\%2Fjournal.pntd.0001814.

5. Gething PW, Patil AP, Smith DL, Guerra CA, Elyazar IR, Johnston GL, Tatem AJ, Hay SI. A new world malaria map: Plasmodium falciparum endemicity in 2010. Malar J. 2011 Dec;10(1):378. https://doi.org/10.1186/1475-2875-10-378.

6. World Health Organization. World malaria report 2017. Geneva: World Health Organization; 2017. https://www.who.int/malaria/publications/worldmalaria-report-2017/en/.

7. Gillies MT, Coetzee M. A Supplement to the Anophelinae of Africa South of the Sahara. Pub/ S Afr Inst Med Res. 1987; 55:1-43.

8. MoH FD. Ethiopia National Malaria Indicator Survey 2015. https://www.google.com/search? $\mathrm{q}=\mathrm{MoH}+$ OF.Ethiopia+National+Malaria+Indicator+Survey+2015.\&sa=X\&ved=0ahUKEwix94rBp7TkAhWkURUIHZmLCzgQ7xYILSgA\&biw=1366\&bih=657. Accessed 5 June 2018 .

9. Ghosh A, Chowdhury N, Chandra G. Plant extracts as potential mosquito larvicides. Indian J Med Res. 2012; 135:581.

10. Balkew M, Gebre-Michael T, Hailu A. Insecticide susceptibility level of Anopheles arabiensis in two agro-development localities in Eastern Ethiopia. Parassitologia. 2003;45:1-3.

11. Yewhalaw D, Wassie F, Steurbaut W, Spanoghe P, Van Bortel W, Denis L, Tessema DA, Getachew Y, Coosemans M, Duchateau L, Speybroeck N. Multiple insecticide resistance: an impediment to insecticide-based malaria vector control program. PLoS One.

2011.https://dx.doi.org/10.1371\%2Fjournal.pone.0016066

12. WHO. Manual on practical entomology in malaria. Part II. Methods and techniques.WHO Division of Malaria and other Parasitic Diseases. 1975. https://apps.who.int/iris/handle/10665/42481.Accessed 6 February 2018.

13. Kibret S, Wilson GG. Increased outdoor biting tendency of Anopheles arabiensis and its challenge for malaria control in Central Ethiopia.Public health.2016; 141:143-5.

14. Shivakumar MS, Srinivasan R, Natarajan D. Larvicidal potential of some Indian medicinal plant extracts against Aedesaegypti (L.).AsianJ Pharm Clin Res. 2013;6:77-80.https://innovareacademics.in/journals/index.php/ajpcr/article/view/114.

15. Maharaj R, Maharaj V, Crouch NR, Bhagwandin N, Folb PI, Pillay P, Gayaram R. Screening of selected ethnomedicinal plants from South Africa for larvicidal activity against the mosquito Anopheles arabiensis. Malar J. 2012;11(1):320. https://doi.org/10.1186/1475-2875-11-320.

16. Dimetry NZ. Prospects of botanical pesticides for the future in integrated pest management programme (IPM) with special reference to neem uses in Egypt. Arch.phytopathol.pfl. .2012; 45:1138-61. https://doi.org/10.1080/03235408.2012.657932.

17. Maharjan S, Shrestha BB, Jha PK. Allelopathic effects of aqueous extract of leaves of Parthenium hysterophorus L. on seed germination and seedling growth of some cultivated and wild herbaceous species. Sci. World J. 2007; 5:33-9.https://doi.org/10.3126/sw.v5i5.2653.

18. McConnachie AJ, Strathie LW, Mersie W, Gebrehiwot L, Zewdie K, Abdurehim A, Abrha B, Araya T, Asaregew F, Assefa F, Gebre-Tsadik R. Current and potential geographical distribution of the invasive plant Parthenium hysterophorus (Asteraceae) in eastern and southern Africa. Weed sci. 2011;51:7184.https://doi.org/10.1111/j.1365-3180.2010.00820.x

19. Datta S, Saxena DB. Pesticidal properties of parthenin (from Parthenium hysterophorus) and related compounds. Pestmanag sci. 2001;57:95101.https://doi.org/10.1002/1526-4998(200101)57:1\%3C95::AID-PS248\%3E3.0.CO;2-J

20. Kumar S, Nair G, Singh AP, Batra S, Wahab N, Warikoo R. Evaluation of the larvicidal efficiency of stem, roots and leaves of the weed, Parthenium hysterophorus (Family: Asteraceae) against Aedes aegypti L. Asian Pac. J. Trop. Dis. 2012;2:395-400.https://doi.org/10.1016/S2222-1808(12)60086-3

21. Bansode PA, Ingole KB, Godase PN, Pawar SG, Bhosale VS. Evaluation of Mosquito Larvicidal Activity of Parthenium hysterophorus (Congress Weed) Against Culex quinquefasciatus.Br J Pharm Res. 2016; 1:29-33.

22. World Health Organization. Guidelines for laboratory and field testing of mosquito larvicides. Geneva: World Health Organization; 2005.https://apps.who.int/iris/bitstream/handle/10665/69101/WHO_CDS_WHOPES_GCDPP_2005.13.pdf. Accessed 6 February 2018.

23. Gomez KA, Gomez KA, Gomez AA. Statistical procedures for agricultural research. $2^{\text {nd }}$ ed. John Wiley \& Sons; 1984.

24. Harborne AJ. Phytochemical methods a guide to modern techniques of plant analysis. ${ }^{\text {rd }}$ ed. Springer science $\&$ business media; 1998.

Page $7 / 10$ 
25. Abbott WS (1925) A method of computing the effectiveness of aninsecticide. J Econ Entomol.18: 265-267.

26. Malarkodi E, Manoharan A. Study on antibacterial activity of Parthenium hysterophorus L. J. chem. pharm. res. 2013; 5:134-6.doi: 10.11648/j.sjac.20150303.11

27. Krishnavignesh L, Mahalakshmipriya A, Ramesh M. In Vitro Analysis of Phytochemical Screening and Antimicrobial Activity of Parthenium hysterophorus L. against pathogenic microorganisms. Asian J Pharm Clin Res. 2013;6:41-4.

28. Ghosh A, Chowdhury N, Chandra G. Plant extracts as potential mosquito larvicides.Indian J. Med. Res. 2012;135:581-598.

29. Patel S. Harmful and beneficial aspects of Parthenium hysterophorus: an update. 3 Biotech. 2011; 1;1(1):1-9.https://dx.doi.org/10.1007\%2Fs13205011-0007-7.

30. Lalitha A, Thangapandiyan S. Mosquito larvicidal efficacy of the acetone leaf extract of Solanum trilobatum against Culex quinquefasciatus and Aedes aegypti. Asian j pharm clin res. 2018;11(12):273-6.

31. Bakar AA, Sulaiman S, Omar B, Ali RM. Screening of Five Plant extracts for Larvicidal efficacy against Larvae of Aedes aegypti (L.) and Aedes albopictus (Skuse). ASM Science Journal. 2018 Jan 1;11(2):103-16.

32. Govindarajan M, Sivakumar R. Larvicidal, ovicidal, and adulticidal efficacy of Erythrina indica (Lam.)(Family: Fabaceae) against Anopheles stephensi, Aedes aegypti, and Culex quinquefasciatus (Diptera: Culicidae). Parasitol. Res. 2014 Feb 1;113(2):777-91. https://doi.org/10.1007/s00436-013-3709-4.

33. Ullah Z, ljaz A, Mughal TK, Zia K. Larvicidal activity of medicinal plant extracts against Culex quinquefasciatus Say.(Culicidae, Diptera). Int. J. Mosq. Res. 2018;5:47-51. DOI: 10.13140/RG.2.2.36501.78565.

34. Wilson E, Chacha M, Omolo JJ, Kidukuli A. Larvicidal activity of leaf and stem extract of Sterculia quinqueloba (Garcke) K. Schum against Anopheles gambiae Giles SS, Culex quinquefasciatus Say and Aedes aegypti mosquito. Am. J. Res. Commun. 2014;2(8):61-71.

35. Sharma A, Kumar S, Tripathi P. Evaluation of the larvicidal efficacy of five indigenous weeds against an Indian strain of dengue vector, Aedes aegypti L. (Diptera: Culicidae). J. Parasitol. Res. 2016. https://doi.org/10.1155/2016/2857089.

36. Macêdo ME, Consoli RA, Grandi TS, Anjos AM, Oliveira AB, Mendes NM, Queiróz RO, Zani CL. Screening of Asteraceae (Compositae) plant extracts for larvicidal activity against Aedes fluviatilis (Diptera: Culicidae). Mem.Inst. Oswaldo. Cruz. 1997; 92:565-70.https://doi.org/10.1590/s007402761997000400024.

37. Suwaiba H, Barde AA, Mao PS, Aliyu OA. Larvicidal activity of Ageratum conyzoides L. extracts on Anopheles gambiae complex. GSC Biological and Pharmaceutical Sciences. 2018;3(3):001-5. https://doi.org/10.30574/gscbps.2018.3.3.0027.

38. Khanna VG, Kannabiran K. Larvicidal effect of Hemidesmus indicus, Gymnema sylvestre, and Eclipta prostrate against Culex qinquifaciatus mosquito larvae. Afr. J. Biotechnol. 2007;6: 307-311.

39. Das NG, Goswami D, Rabha B. Preliminary evaluation of mosquito larvicidal efficacy of plant extracts. J Vect Borne Dis. 2007 Jun 1;44(2):145.

40. Mohan L, Sharma P, Shrivastava CN. Evaluation of Solanum xanthocarpum extract as a synergist for cypermethrin against larvae of filarial vector Culex quinquefasciatus. Entomol Res. 2006; 36:220-5. https://doi.org/10.1111/j.1748-5967.2006.00037.x.

41. 41. Francine TN, Cabral BN, Anatole PC, Bruno MM, Pauline N, Jeanne NY. Larvicidal activities of hydro-ethanolic extracts of three Cameroonian medicinal plants against Aedes albopictus. Asian J. Trop. Biomed. 2016 Nov 1;6(11):931-6. https://doi.org/10.1016/j.apjtb.2016.09.004

42. Muhammad B, Khan R, Arshad Y, Khan RA. Phytochemical and cytotoxic analysis of Pharthenium hysterophosis selected from District Bannu, Pakistan.Afr. J. Biotechnol. 2012;11:11857-60.http://dx.doi.org/10.5897/AJB11.2109

\section{Figures}



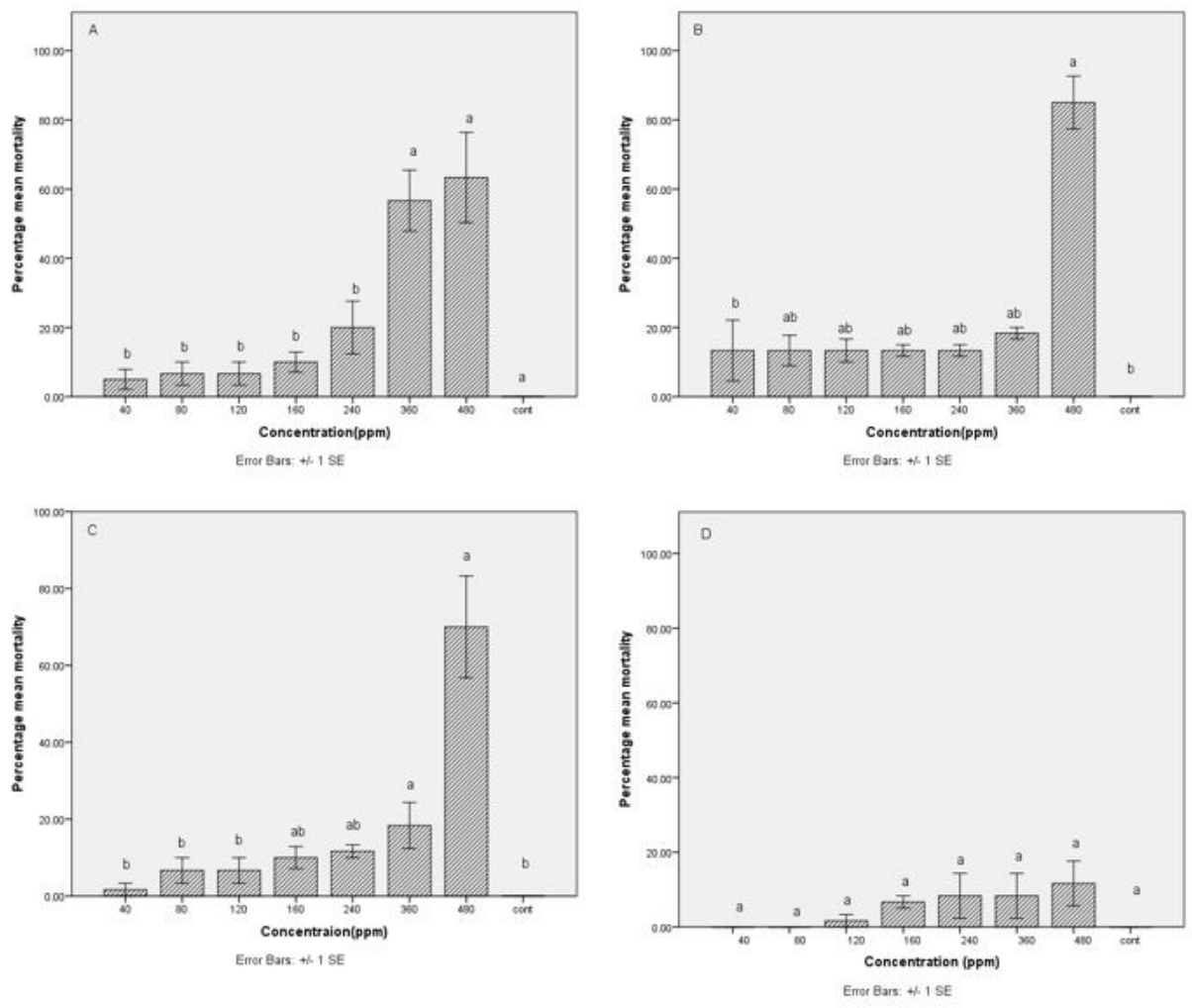

Figure 1

Percentage mean mortality of 4th instar larvae of An. arabiensis with different concentrations of petroleum ether (A) hexane (B) acetone (C) and ethanol (D) extracts of P. hysterophorus leaves. The mean percentage larval mortalities with different letter designations are significantly different from one another with a Tukey HSD post hoc analysis at significance level $(P<0.05)$. Error bars represent the standard error of the mean.
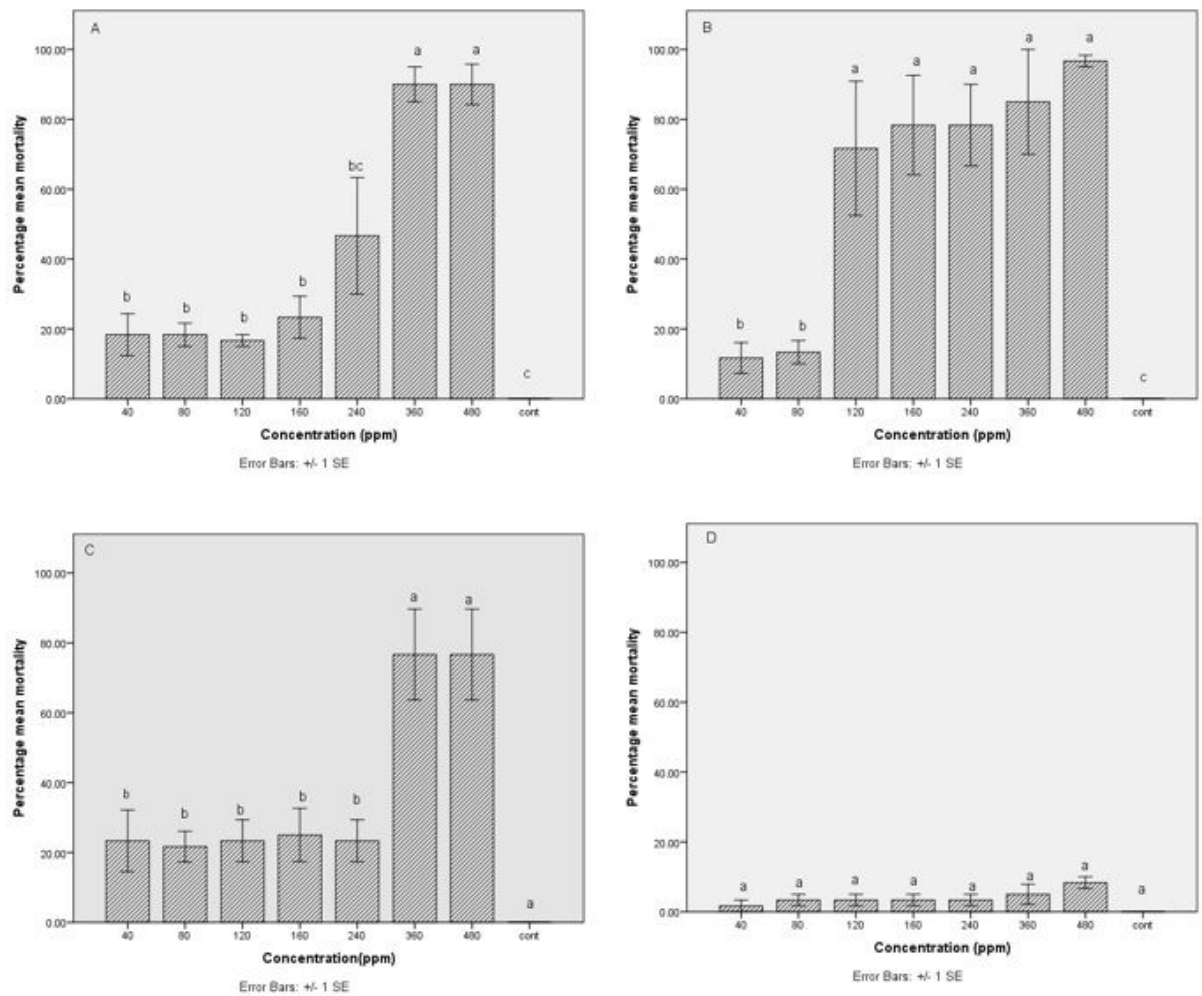

Figure 2 
Percentage mean mortality of fourth instar larvae of An. arabiensis with petroleum ether (A) hexane (B) acetone (C) and ethanol (D) extracts of P. hysterophorus stem. The mean percentage larval mortalities with different letter designations are significantly different from one another with a Tukey HSD post hoc analysis at significance level $(P<0.05)$. Error bars represent the standard error of the mean.
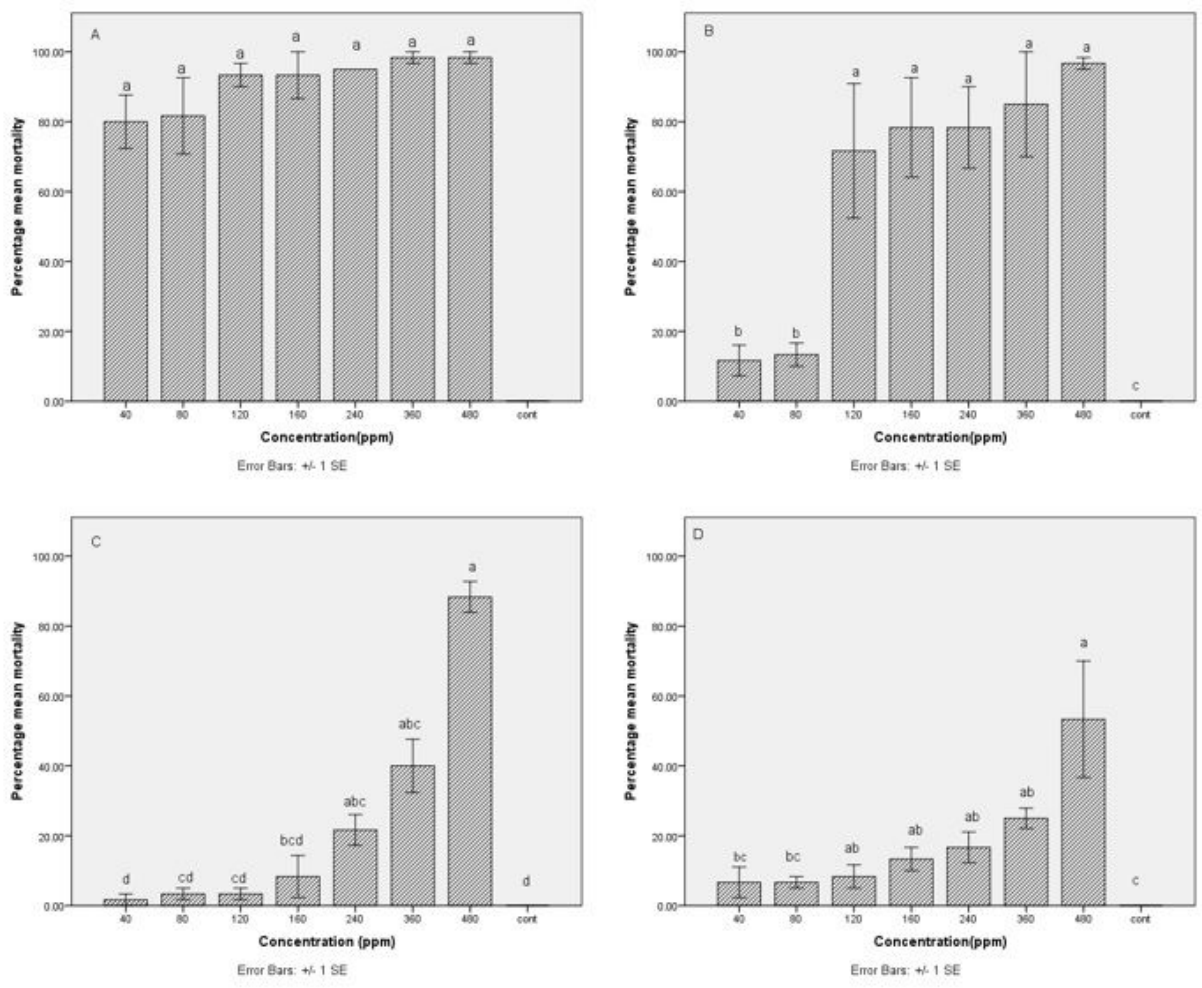

\section{Figure 3}

Percentage mean mortality of fourth instar larvae of An. arabiensis with petroleum ether (A) hexane (B) acetone (C) and ethanol (D) extracts of P. hysterophorus root. The mean percentage larval mortalities with different letter designations are significantly different from one another with a Tukey HSD post hoc analysis at significance level $(P<0.05)$. Error bars represent the standard error of the mean. 